\title{
Free radical scavenger offers protection against oxidative stress in diabetic kidney
}

\author{
Flori R. Sari, Citra Humairah, Rizkiani Juleshodia \\ Department of Pharmacology \\ Medical Faculty, State Islamic University Syarif \\ Hidayatullah \\ Jakarta, Indonesia \\ florirsari@uinjkt.ac.id
}

\author{
Rajarajan A. Thandavarayan \\ Department of Cardiovascular Sciences \\ Houston Methodist Research Institute, Center for \\ Cardiovascular Regeneration \\ Houston, Texas, USA
}

\author{
Vivian Soetikno, Wawaimuli Arozal \\ Department of Pharmacology \\ Medical Faculty, University of Indonesia \\ Jakarta, Indonesia
}

\author{
Kenichi Watanabe, Somasundaram Arumugam \\ Department of Hematology Endocrinology and Metabolism \\ Niigata University, Graduate School of Medical and Dental \\ Sciences \\ Niigata, Japan
}

\begin{abstract}
Oxidative stress plays pivotal roles in heightening the pathology of diabetic nephropathy. Widely known free radical scavenger, edaravone (3-methyl-1-phenyl-2-pyrazoline-5one), has been proven to give benefits in cardiovascular and brain diseases by attenuating oxidative stress. Additionally, whether this drug give benefits in the diabetic nephropathy remains unclear. To investigate the roles of free radical scavenger on oxidative stress markers in the diabetic nephropathy.

Methods. C57BL/6 mice were subjected to 56 days diabetes mellitus induced by streptozotocin. Three and ten $\mathrm{mg} / \mathrm{kg} \mathrm{BW}$ edaravone was given by intraperitoneal injection twice daily for 28 days. Renal oxidative stress and treatment efficacies were analyzed by TBARS, western blot, immunohistopathology and TUNEL Assay. Body weight reduction was observed in all diabetic group. Edaravone did not improve the body weight loss, however, it significantly reduced blood glucose level in the diabetic mice. Additionally, significant reduction of MDA level was observed in the group received edaravone treatment. Renal fibrosis, apoptosis as well as protein expression of p22 and p67phox were significantly increased in the diabetic mice. Edaravone treatment significantly attenuated renal fibrosis, apoptosis and oxidative stress. These results suggest that oxidative stress plays important roles in the pathology of diabetic nephropathy and free radical scavenger protects the kidney against oxidative stress at least in part through the inhibition of p22 and p67-phox expressions. Conclusively, treatment of free radical scavenger may become novel strategy in the prevention of diabetic kidney complications.
\end{abstract}

Keywords- diabetes, nephropathy, apoptosis, oxidative stress, free radical scavenger

\section{INTRODUCTION}

Diabetic nephropathy is a microvascular complication of diabetes which is characterized by microalbuminuria, glomerular hypertrophy, tubular atrophy, interstitial fibrosis and arteriolar thickening. This complication causes around
$44 \%$ of all cases of end-stage renal disease and renal failure in the diabetic patients in the United States [1]. Molecular mechanism of diabetic nephropathy includes persistent hyperglycemia which further stimulates the activation of advanced glycation end products (AGEs), chronic inflammation and reactive oxygen species (ROS) [2]. Additionally, NADPH oxidases have been implicated for increased generation of ROS in the diabetic nephropathy $[3,4]$. Edaravone (3-methyl-1-phenyl-2-pyrazolin-5-one), a strong novel free radical scavenger, offers protection to various cells by enhancing prostacyclin production, trapping hydroxyl radicals, quenching active oxygen [5]. We have reported that edaravone gave beneficial effect in the treatment of dilated cardiomyopathy [6]. Furthermore, edaravone have been reported to improve cardiovascular diseases [7,8], diabetic retinopathy [9], and lipid-associated diabetic nephropathy [10]. In the present study, we investigate the role of edaravone in vivo on oxidative stress and NADPH oxidases in the 56 days streptozotocin-induced mice.

\section{Methodology}

\section{A. Diabetes induction and edaravone treatment}

Streptozotocin (STZ; Sigma-Aldrich, Inc., St. Louis, MO, USA) was dissolved in $20 \mathrm{mM}$ sodium citrate saline buffer $(\mathrm{pH}$ 4.5) as previously described and administered by a single intraperitoneal injection at a dose of $150 \mathrm{mg} / \mathrm{kg}$ body weight (BW) within 5 minutes of preparation to 8-10 week old male C57BL/6 mice [11]. The random (non-fasting) blood glucose level was measured at one week after STZ injection using Medi-safe chips (Terumo, Inc., Tokyo) and mice with a blood glucose level of higher than $300 \mathrm{mg} / \mathrm{dl}$ were considered to be diabetic. At 28 days after diabetic condition, diabetic mice were divided into three groups and given twice daily intraperitoneal injection with either edaravone $3 \mathrm{mg} / \mathrm{kg} \mathrm{BW}$ $(\mathrm{E} 3 ; \mathrm{n}=4)$ or edaravone $10 \mathrm{mg} / \mathrm{kg} \mathrm{BW} \mathrm{E10;n=6)}$ or vehicle 
(D; $n=7)$ for 28 days. Edaravone (3-methyl-1-phenyl-2pyrazoline-5-one) was synthesized at the Research Center of Mitsubishi Chemical Industries Ltd. Age matched C57BL/6 mice were injected with $100 \mu \mathrm{l}$ of citrate buffer and used as the non-diabetic controls $(C ; n=5)$. The control, D, E3 and E10 groups were sacrificed at day 56 after diabetes condition. During the experiment, the mice were allowed free access to water and chow throughout the study period. The mice were treated in strict accordance with the recommendations of the Declaration of Helsinki and the guidelines for animal experimentation of our institute.

\section{B. Malondialdehyde (MDA) analysis}

MDA was analyzed by TBARS method. The sensitivity of measuring MDA has made this assay the method of choice for screening and monitoring lipid peroxidation, a major indicator of oxidative stress. Renal tissues were rinsed, weighed, resuspended at $50 \mathrm{mg} / \mathrm{ml}$ in normal saline and homogenized. After centrifugation at $3000 \mathrm{r} / \mathrm{min}$ for $10 \mathrm{~min}$ at 4 degree $\mathrm{C}$, the supernatants were collected and analyzed with corresponding assay kits (Oxitex, ZeptoMetrix Corporation, New York, U.S.A)

\section{Azan-Mallory staining}

The area of renal fibrosis in Azan-Mallory-stained renal tissue sections was quantified using a color image analyzer (CAI-102; Olympus) by measuring the blue fibrotic areas compared to the red area at 200x magnification.

\section{Terminal deoxynucleotidyl transferase-mediated dUTP nick-end labeling (TUNEL)}

TUNEL analysis was performed as specified in the in situ apoptosis detection kit (Takara Bio Inc., Shiga, Japan). To quantify apoptotic cells, the percentage of TUNEL positive cells was measured at 200x magnification in thirty randomly chosen fields of each three replicates from three samples. The proportion of TUNEL-positive cells was expressed as a percentage of the total cells counted. All digital photographs were taken using the color image analyzer (CAI-102; Olympus).

\section{E. Protein analysis by Western blotting}

Protein lysate was prepared from renal tissue. The total protein concentrations of the samples were measured by the bicinchoninic acid (BCA) method. For Western blot analysis, $30 \mu \mathrm{g}$ of total protein were loaded and separated by SDSPAGE, before being electrophoretically transferred to nitrocellulose filters. The filters were then blocked with $5 \%$ non-fat dry milk in Tris-buffered saline (20mM Tris (pH 7.6) and $137 \mathrm{mM} \mathrm{NaCl}$ ) and $0.1 \%$ Tween 20, washed, and then incubated with primary antibody. The primary antibodies employed were NADPH oxidases subunits p22 phox and p67 phox. All antibodies were purchased from Santa Cruz Biotechnology Inc. (CA, U.S.A). For Western blot analysis, all primary antibodies were used at dilution of 1:1000, and the secondary antibodies were used at a dilution of 1:5000. After incubation with the primary antibody, the bound antibody was visualized with horseradish peroxidase-coupled secondary antibodies (Santa Cruz Biotechnology, Inc) and chemiluminescence developing agents (Amersham Biosciences, Amersham, Buckinghamshire, UK). The films were then scanned using a GT-X700 scanner (Epson, Tokyo, Japan), and band densities were quantified by densitometric analysis using Scion image software (Scion Corporation, Frederick, Maryland, USA).The level of expression of each protein in the control mice was taken as one arbitrary unit (AU).

\section{F. Statistical analysis}

Data are presented as means and standard error (SE). Comparison among groups was performed using Student's ttest or one-way analysis of variance (ANOVA) followed by Tukey-Kramer post hoc analysis method, wherever applicable. Differences were considered as statistically significant at probability value $<0.05$.

\section{RESULTS}

\section{A. Blood glucose level and body weight changes}

After 28 days of diabetic condition, blood glucose level was significantly increased in the D, E3 and E10 group when compared to the control group. Twenty eight days treatment of 3 or $10 \mathrm{mg} / \mathrm{kg}$ BW edaravone started on day 28 significantly decreased blood glucose level eventhough the reduction did not reach normal level (Table 1). Significant body weight reduction was observed in the $\mathrm{D}, \mathrm{E} 3$ and E10 group when compared to the control group. Twenty eight days treatment of 3 and $10 \mathrm{mg} / \mathrm{kg}$ BW edaravone started on day 28 did not protect the loss of the body weight (Table 1).

\section{B. MDA analysis}

MDA represents as the marker of oxidative stress. On day 56 , the average of renal MDA level was significantly higher in the D group when compared to the control group. Groups that received 28 days of 3 or $10 \mathrm{mg} / \mathrm{kg} \mathrm{BW}$ edaravone had lower renal MDA level when compared to the D group $(\mathrm{p}<0.05$, Fig.1).

TABLE I. BLOOD GLUCOSE LEVEL AND BODY WEIGHT CHANGES

\begin{tabular}{|c|c|c|c|}
\hline $\begin{array}{l}\text { Parameter in the } \\
\text { group }\end{array}$ & Day 1 & Day 28 & Day 56 \\
\hline $\begin{array}{l}\text { Blood glucose } \\
\text { C } \\
\text { D } \\
\text { E3 } \\
\text { E10 }\end{array}$ & $\begin{array}{l}149 \pm 40 \\
127 \pm 17 \\
140 \pm 14 \\
126 \pm 17\end{array}$ & $\begin{array}{c}142 \pm 22 \\
549 \pm 87 * * \\
600 \pm 0.00 * * \\
600 \pm 0.00 * *\end{array}$ & $\begin{array}{l}162 \pm 26 \\
600 \pm 0^{* *} \\
498 \pm 119^{\#} \\
494 \pm 87^{\# \#}\end{array}$ \\
\hline $\begin{array}{l}\text { BW } \\
\text { C } \\
\text { D } \\
\text { E3 } \\
\text { E10 }\end{array}$ & $\begin{array}{l}100 \% \pm 0.00 \\
100 \% \pm 0.00 \\
100 \% \pm 0.00 \\
100 \% \pm 0.00\end{array}$ & $\begin{array}{c}106 \% \pm 5 \\
89 \% \pm 4 * * \\
88 \% \pm 10 * * \\
82 \% \pm 4 * *\end{array}$ & $\begin{array}{l}115 \% \pm 8 \\
97 \% \pm 9^{* *} \\
91 \% \pm 11 * * \\
80 \% \pm 7 * *\end{array}$ \\
\hline \multicolumn{4}{|c|}{$\begin{array}{l}\mathrm{C}=\text { control; } \mathrm{D}=\text { diabetic group with vehicle; } \mathrm{E} 3=\text { diabetic group with } 3 \\
\mathrm{mg} / \mathrm{kg} \mathrm{BW} \text { edaravone; } \mathrm{E} 10=\text { diabetic group with } 10 \mathrm{mg} / \mathrm{kg} \mathrm{BW} . \\
* * \mathrm{p}<0.01 \text { vs control }(\mathrm{C}) \text { group, } \# \# \mathrm{p}<0.01 \text { and } \# \mathrm{p}<0.05 \mathrm{vs} \mathrm{D} \text { group }\end{array}$} \\
\hline
\end{tabular}




\section{TUNEL and fibrosis analysis}

Excessive oxidative stress may activate cell death. From the TUNEL analysis, we have found that on day 56, the average of renal apoptosis was significantly higher in the D group when compared to the control group. Groups that received 28 days of 3 or $10 \mathrm{mg} / \mathrm{kg} \mathrm{BW}$ had a significant lower renal apoptosis when compared to the D group (Fig.2).

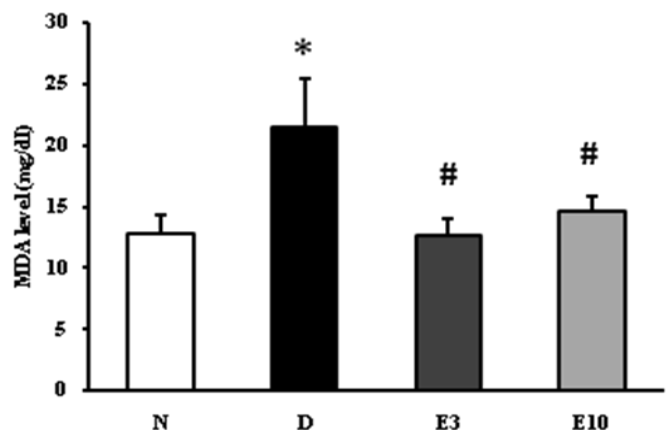

Fig. 1 MDA level of the C, D, E3 and E10 in $\mathrm{mg} / \mathrm{dl}$. C = control; D = diabetic group with vehicle; E3 = diabetic group with $3 \mathrm{mg} / \mathrm{kg}$ BW edaravone; E10 = diabetic group with $10 \mathrm{mg} / \mathrm{kg} \mathrm{BW}$. *p<0.05 vs control (C) group, \# $\mathrm{p}<0.05$ vs D group
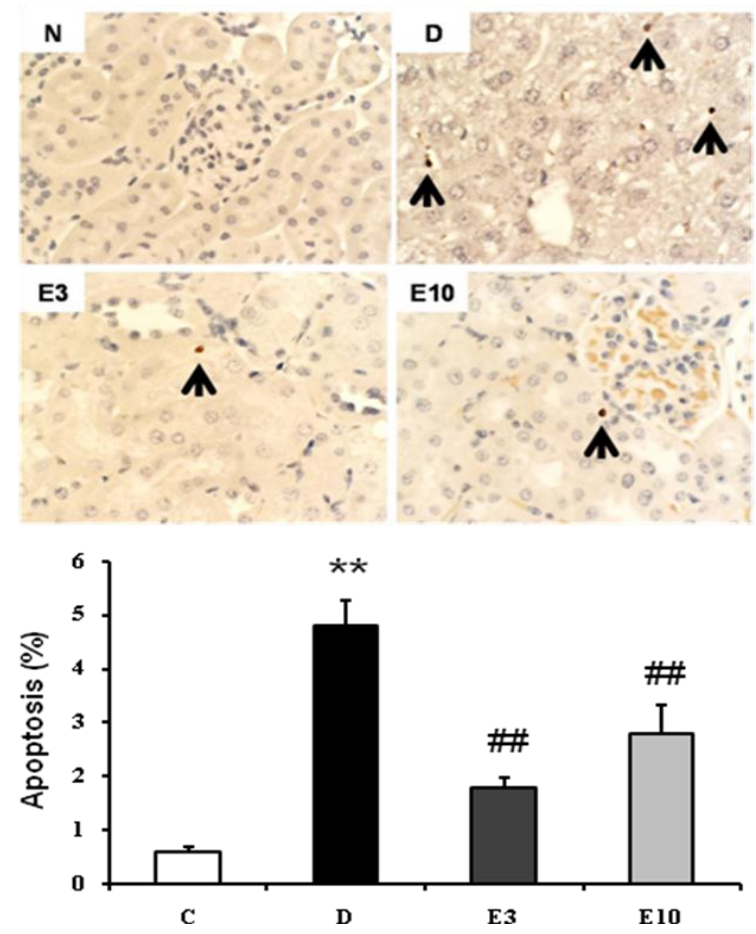

Fig. 2 Renal apoptosis level of the C, D, E3 and E10 in percentage. C = control; $\mathrm{D}=$ diabetic group with vehicle; $\mathrm{E} 3=$ diabetic group with $3 \mathrm{mg} / \mathrm{kg}$ $\mathrm{BW}$ edaravone; $\mathrm{E} 10=$ diabetic group with $10 \mathrm{mg} / \mathrm{kg} \mathrm{BW}$. **p $<0.01 \mathrm{vs}$ control (C) group, \#\# $\mathrm{p}<0.01$ vs $\mathrm{D}$ group

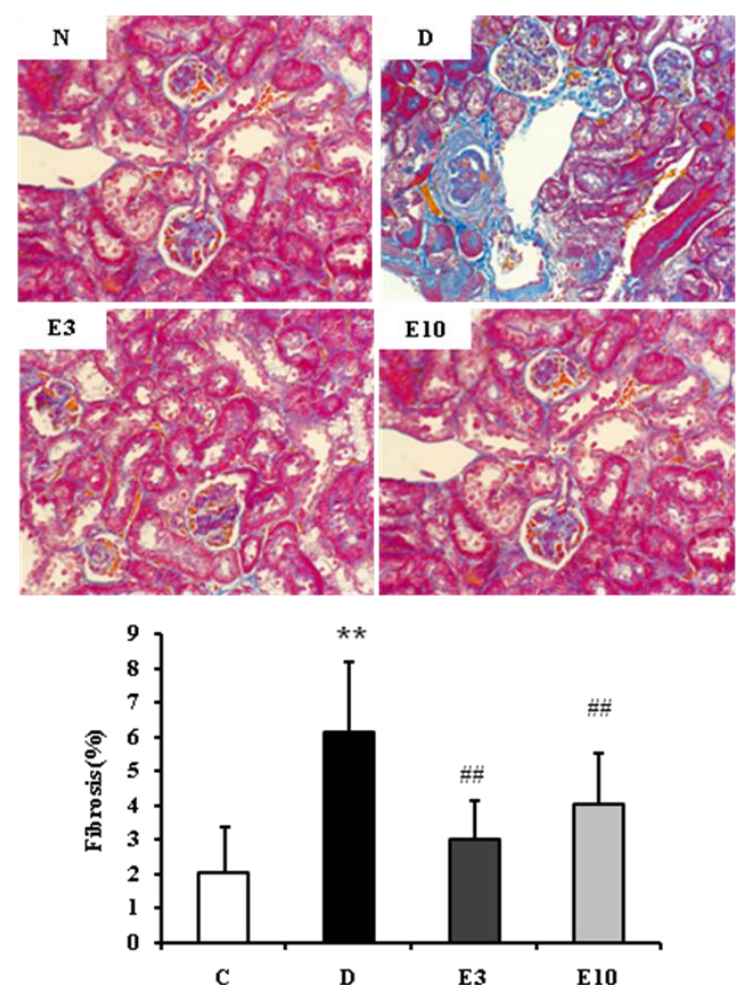

Fig. 3 Renal fibrosis level of the C, D, E3 and E10 in percentage. C = control; D = diabetic group with vehicle; $\mathrm{E} 3=$ diabetic group with $3 \mathrm{mg} / \mathrm{kg}$ BW edaravone; $\mathrm{E} 10=$ diabetic group with $10 \mathrm{mg} / \mathrm{kg} \mathrm{BW}$. **p $<0.01 \mathrm{vs}$ control (C) group, \#\# p<0.01 vs D group

\section{Western blot analysis}

From the western blot analysis, we have found that on day 56, the expression of renal p22phox and p67phox was significantly higher in the D group when compared to the control group. Groups that received 28 days of 3 or $10 \mathrm{mg} / \mathrm{kg}$ BW edaravone had lower expression of renal p22phox and p67phox when compared to the D group ( $p<0.01$, Fig.4).

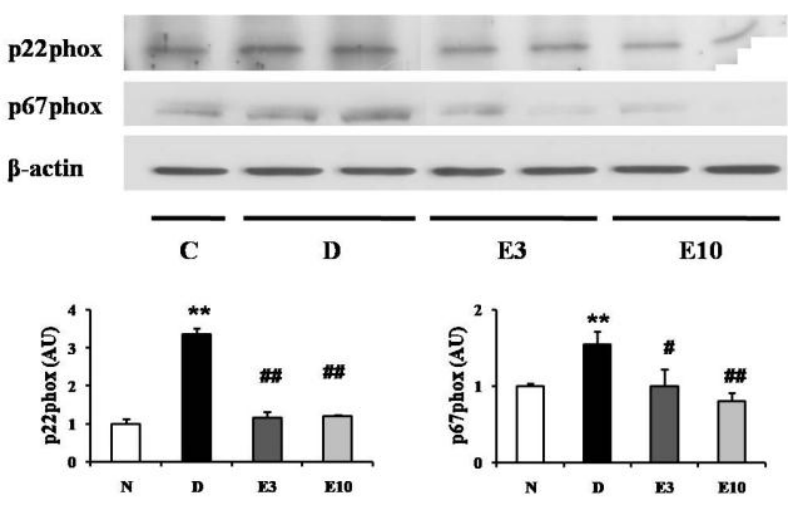

Fig. 4 Renal expressions of the NADPH oxidases subunit in the C, D, E3 and E10 in arbitrary unit (AU). $\mathrm{C}=$ control; $\mathrm{D}=$ diabetic group with vehicle; $\mathrm{E} 3=$ diabetic group with $3 \mathrm{mg} / \mathrm{kg} \mathrm{BW}$ edaravone; E10 = diabetic group with 10 $\mathrm{mg} / \mathrm{kg} \mathrm{BW}$. ${ }^{*} \mathrm{p}<0.01$ vs control (C) group, \# $\mathrm{p}<0.05$ and \#\# $\mathrm{p}<0.01$ vs D group 


\section{DISCUSSION}

Molecular mechanism of diabetic nephropathy includes persistent hyperglycemia that further stimulates the activation of AGEs and results in the appearance of chronic inflammation and oxidative stress [2]. We have demonstrated that MDA level, analyzed by TBARS, as well as blood glucose level were increased on day 56 of diabetes melitus, suggesting a strong correlation between hyperglycemia condition and the oxidative stress formation. Additionally, we have confirmed the tissue oxidative stress by western blot technique and found that the expression of NADPH oxidases subunit, p22phox and p67phox, were significantly expressed in the diabetic group. Consistent with our findings, the persistent oxidative stress stimulated tissue damages which further manifested as fibrotic or apoptotic cells.

Edaravone, a novel free radical scavenger have been reported to counteract the destructive effect of STZ on the pancreas which results in the complete inhibition of ROS formation [12]. We have shown that 28 days treatment of edaravone on 56 days diabetic protocol gave beneficial effect on blood glucose level as well as reduction of renal MDA level, inhibition of renal p22phox and p67 phox expressions and reduction of renal apoptosis and fibrosis.

Therefore, edaravone protects the kidney complication in the diabetes melitus, at least in part through the inhibition of renal NADPH oxidases subunit $[4,10]$.

\section{ACKNOWLEDGMENT}

We would like to thank Yujin Memorial Grant; the Ministry of Education, Science, Sports, and Culture of Japan; and the Promotion and Mutual Aid Corporation for Private Schools of Japan.

\section{REFERENCES}

[1] J.E. Shaw, R.A. Sicree and P.Z. Zimmet, "Global estimates of the prevalence of diabetes for 2010 and 2030," Diabetes Research and Clinical Practice, vol. 87, pp. 4-14, 2010.

[2] G. Manda, A.I. Checherita, M.V. Comanescu and M.E Hinescu, "Redox signaling in diabetic nephropathy: hypertrophy versus death choices in mesangial cells and podocytes," Mediators Of Inflammation, vol. 2015, pp. 13, 2015.

[3] N. Kashihara, Y. Haruna, V.K. Kondeti, Y.S Kanwar, "Oxidative stress in diabetic nephropathy," Curr. Med. Chem. vol. 17, pp. 4256-4269, 2010.

[4] M. Satoh, S. Fujimoto, Y. Haruna, S. Arakawa, H. Horike, N. Komai, et al, "NAD $(\mathrm{P}) \mathrm{H}$ oxidase and uncoupled nitric oxide synthase are major sources of glomerular superoxide in rats with experimentaldiabetic nephropathy," Am. J. Physiol. Renal. Physiol. vol. 288, pp.F1144-1152, 2005.

[5] Y. Higashi, D. Jitsuiki, K. Chayama, M. Yoshizumi, "Edaravone (3-methyl-1-phenyl-2-pyrazolin-5-one), a novel free radical scavenger, for treatment of cardiovascular diseases,' Recent. Pat. Cardiovasc. Drug. Discov, vol. 1, pp. 85-93, Jan 2006.

[6] S. Arumugam, R.A. Thandavarayan, P.T. Veeraveedu, T. Nakamura, W. Arozal, F.R. Sari, et al, "Beneficial effects of edaravone, a novel antioxidant, in rats with dilated cardiomyopathy," vol. 16. pp. 2176-2185, Sep 2012.

[7] K. Kikuchi, S. Tancharoen, N. Takeshige, M. Yoshitomi, M. Morioka, Y. Murai, E. Tanaka, "The efficacy of edaravone (radicut), a free radical scavenger, for cardiovascular disease,” Int. J. Mol. Sci, vol. 14, pp.13909-13930, Jul 2013.

[8] L. Ji, Y. Liu, Y. Zhang, W. Chang, J. Gong, S. Wei, et al, "The antioxidant edaravone prevents cardiac dysfunction by suppressing oxidative stress in type 1 diabetic rats and in high-glucose-induced injured H9c2 cardiomyoblasts," Can. J. Physiol. Pharmacol, vol 94, pp. 996-1006, Sep 2016

[9] D. Yuan, Y. Xu, H. Hang, X. Liu, X. Chen, P. Et al, "Edaravone protect against retinal damage in streptozotocininduced diabetic mice," PLoS One, vol. 9, pp. e99219. Jun 2014.

[10] R. Varatharajan, L.X. Lim, K. Tan, C.S. Tay, Y.L. Teoh, S.S. Akhtar, "Effect of edaravone in diabetes mellitus-induced nephropathy in rats," Korean. J. Physiol. Pharmacol, vol. 20, pp.333-340, Jul 2016.

[11] F.R. Sari, K. Watanabe, R.A. Thandavarayan, M. Harima, S. Zhang, A.J. Muslin, "14-3-3 protein protects against cardiac endoplasmic reticulum stress (ERS) and ERS-initiated apoptosis in experimental diabetes," J. Pharmacol. Sci, vol. 113, pp. 325 - 334 Jul 2010.

[12]D. Fukudome, M. Matsuda, T. Kawasaki, Y. Ago, T. Matsuda,"The radical scavenger edaravone counteracts diabetes in multiple low-dose streptozotocin-treated mice,” Eur. J. Pharmacol, vol. 583, pp. 164-169, Mar 2008. 